\title{
A review of the motivations of corporate strategic change - based on the perspective of senior management
}

\author{
Xiaoxiao Kong ${ }^{1, a}$, Lei Zhu ${ }^{2, b, *}$ \\ ${ }^{1}$ Nanjing University of Science and Technology, Nanjing \\ ${ }^{2}$ Nanjing University of Science and Technology, Nanjing \\ a563041472@qq.com, b1103204132@qq.com \\ * Xiaoxiao Kong
}

\section{Keywords: Strategic change, Motivation, senior management}

\begin{abstract}
Based on senior management perspectives, this article reviews the representative literature on the causes of corporate strategic change from the perspectives of senior management traits, CEO changes, and entrepreneur cognition and psychological capital, and finally the paper draws the conclusion, points out the innovation and lack, and prospects for the future research.
\end{abstract}

\section{Introduction}

In the face of increasingly fierce competition and rapidly changing internal and external environments, companies must enter new market areas or gradually withdraw from existing markets that are difficult to adapt. The motivation theory of strategic change attempts to explore the motivational mechanism that drives the strategic transfer of companies between different markets, and provides fundamental guidance for the strategic transformation of enterprises [1]. In the current study, the focus of corporate strategic change drivers is the external environment of business operations, the evolution and transformation of organizations, the changes in organizational resources, and the promotion of organizational learning. Senior managers play an important role in the formulation and implementation of corporate strategy and bear the important responsibility of initiating and implementing strategic changes. This article sorts out the reasons for the strategic changes of senior management perspectives from the following three aspects.

\section{The characteristics of top management team}

The characteristics of the top management team are manifested in many aspects. First, in the composition of top management teams, the demographic characteristics of members involved in senior management teams usually include age, education level, tenure, and professional experience. For example, Wiersema et al. [2] used the data of 199 bank senior executives in the United States to analyze the influence of age composition on corporate strategic change. The results showed that the younger executive teams are more inclined to implement strategic changes. Smith [3] examined the influence of the background of professional training of the senior management team on the organizational process and found that there is a significant positive correlation between the quality of the professional background of the senior management team and the organizational strategy change. Finkelstein [4] examined the senior management team tenure, strategic changes and the impact on corporate performance and found that the longer the senior executive team tends to adopt a consistent, unchanging strategy, the company's performance is also closer to the industry average. The level, especially in the turbulent external environment, is particularly pronounced. In the study of the influence of team members' professional experience on strategic changes, scholar Sambharya [5] studied the results of U.S. multinational corporations, showing that overseas experiences of senior management team members will have a positive impact on the company's internationalization strategy. The research of Carpenter [6] shows that the experience of internationalization of CEO and executive team members has a positive impact on corporate performance. When executive team 
members and board members have international experiences, companies are more inclined to pursue global strategic positioning. This shows that the professional experience of the members of the senior management team will have an impact on the relationship between strategic changes (including internationalization strategies) and corporate values.

Homogeneity and heterogeneity among top management team members also have an impact on corporate strategic change. For example, Bantel [7] showed that the more diverse the members of the executive team are in terms of education and professional background, the more likely they are to make good strategic decisions. This is also related to the industry and the external environment in which the company is located. The stability or change of the industry environment in which the company is located will have an impact on the relationship between strategic changes and the value of the company. Richard [8] used a sample of Fortune 500 industrial companies and found that in the high-stability industry, there is a positive correlation between the senior management team tenure, education background, job background heterogeneity, and the strategic positioning of the company's globalization. In high-uncertainty industries, the term and job background heterogeneity have a negative impact on global operations. As a result, when examining the impact of the executive team on strategic change and corporate value relationships, a more rigorous study should consider the impact of social environmental factors in which team members are embedded. Future research on top management teams and strategic change requires more empirical research and case studies to better examine the specific mechanisms that have taken place between the two.

\section{CEO turnover}

As the core of the top management team, the role of the CEO in the strategic change has drawn widespread attention from scholars early on. There are many researches on CEO's demographic characteristics such as age, gender, professional background education background and so on, which have influence on CEO's administrative ability and organizational performance. With the development of the economic situation, the external environment of enterprises has increasingly exhibited volatile, uncertain, complex, and vague mutation characteristics. This kind of mutation environment poses new challenges to the strategic transformation of enterprises, and existing CEOs tend to favor Continuing the existing strategy leads to a mismatch between the internal and external environment of the company and can easily cause differences and conflicts between the internal board of directors and senior management personnel. CEO change has become the focus of academic attention.

Keck and Tushman in the 1993 study focused on the CEO turnover will lead to changes in the company's management team, team heterogeneity. The studies of Deniss (1995) and Miller (1993) also confirmed that new CEOs usually make strategic decisions that are different from those of their predecessors. Changes in CEOs trigger large-scale strategic adjustments. Domestic scholar Liu Xin (2013) combined agent theory and organizational theory to propose that the new CEO tends to initiate strategic changes related to the pressure environment and personal risk preferences of the board he is facing [9].

However, changes in the CEO do not necessarily lead to strategic changes. An important focus of CEO change perspective is the source of the new CEO. Friedman and Saul (1991) found in the study of manufacturing and apparel industry that external successors are more likely to cause changes in senior management teams than internal successors. Wiersema's (1992) study also shows that the source of the CEO has a significant impact on the CEO strategy after the change: the external CEO is more likely to initiate the corporate strategy change than the internal CEO. Zhang and Rajagopalan (2003) extended their research to non-diversified companies. They also found that new CEOs from internal companies are more likely to stick to their original strategies. Scholar Liu Xinmin detailed the internal succession study as internal followers and internal competitors. The study found that internal follower succession is negatively related to the reorganization of senior management team and strategic change. Internal competitor succession and outsider succession and senior management team reorganization and strategy Change is positively related [10]. In the CEO change impact 
mechanism, Farrell and Whidbee (2002) found that in addition to influencing the new director candidates, the new CEO will also affect the board of directors. It can be seen from this that CEO changes often imply changes in the work of the board of directors and senior management teams and even the reorganization of personnel. These changes also promoted the strategic changes of the company.

Through reviewing and reviewing existing relevant research literature abroad, it can be seen that the strategic change research based on CEO change perspective mainly revolves around "why" (ie, the motivation for the new CEO to make strategic changes) and "how" (ie, the new CEO is conducting the strategy. What factors are affected by the change process?). Existing studies have focused on the internal drivers of the new CEO strategic change, and there has been insufficient attention to the external drivers of the new CEO strategic change. Therefore, future research should not stop at explaining the motivation of the new CEO's strategic change from the perspective of cognitive psychology but should pay more attention to the external motives that drive the new CEO to initiate strategic change, so as to broaden the scope of research on the motivation of the new CEO strategic change. Build a more comprehensive, three-dimensional theoretical framework for the new CEO strategic change.

\section{Entrepreneur cognition and psychological capital}

Since the study of Hambrick and Mason (1984) pointed out that entrepreneurial cognition will affect business decision-making and competitiveness, more and more scholars in the field of strategic management have started to pay attention to entrepreneurship cognition. The current research focus on entrepreneurship cognition mainly focuses on its impact on the company's strategic performance, corporate dynamic capabilities, business model choices and other consequential variables. Entrepreneurial cognition is the boundary of corporate behavior, which determines the ability of the enterprise to pursue and obtain competitive advantage (Gavetti \& Greve, 2012). Laamanen and Wallin (2009) studied the impact of management cognition on dynamic capabilities and found that managers' vision will affect the shaping of corporate capabilities. Chanda (2015) believes that the idea of individual managers is an important mediator of the interaction between individual managers and the environment. Bergman (2015) points out that entrepreneurial attitudes, beliefs, and ability to create meaning influence organizational management processes. The dominant logic and innovation activities are interactive. Helfat (2015) proposed that the CEO's external social network will affect its cognition, mainly reflected in the recognition of strategic models and self-efficacy in the identification of opportunities, which will affect the strategic flexibility and organizational performance [11].

Compared with foreign studies, the current domestic research on entrepreneurial cognition is still in the stage of development. Scholars who explicitly put forward the concept of entrepreneurship are less. Yang Lin (2010) believes that in the process of corporate strategic change, entrepreneurs are the main sponsor and leader. The entrepreneurial cognition as a strategic resource of a company will have a direct impact on the strategic change of the company. Su Jingqin and Cui Wei (2011) believe that the heterogeneity of entrepreneurial cognitive resources will have an impact on management innovation decisions. Zhou Xiao-hu (2014) believe that the so-called entrepreneurial cognition (entrepreneur cognition) is the knowledge structure for entrepreneurs to evaluate, judge, and make decisions on key business issues such as business opportunities, venture capital, and corporate growth. In addition, domestic scholars also proceed from the study of psychology and try to uncover the psychological mechanism of entrepreneurship. Through case studies, they found that entrepreneurial perception can be influenced by positive emotions that affect entrepreneurial perception and ultimately influence the outcome of change. In a word, the research on the motivation of corporate strategic change from the current cognitive perspective is not comprehensive. There is no theoretical model and there is no relevant empirical research. There is a lot of research space in the future. 


\section{Summary}

The motivation for corporate strategic change has long been a hot topic for strategic scholars. The development of research on the causes of change has evolved from macroscopic to microscopic, external to internal, and organizational to personal. Future research should be based on specific contexts, concrete analysis of the specific causes of enterprise-initiated changes in different contexts, and more attention can be paid to entrepreneurial awareness and psychological capital. In my opinion, the corporate strategy change is not entirely an objective process. Whether senior management can recognize and identify changes in the environment, make correct responses to changes, and seize opportunities are important factors in the success of corporate transformation.

\section{References}

[1] Sull D N. Closing the Gap Between Strategy and Execution[J]. Mit Sloan Management Review, 2007, 48(4):págs. 30-38.

[2] Wiersema, M. F., \& Bantel, K. A. (1992). Top Management Team Demography and Corporate Strategic Change. (Vol.35, pp.91-121).

[3] Smith K G, Smith K A, Olian J D, et al. Top Management Team Demography and Process: The Role of Social Integration and Communication. Administrative Science Quarterly, 1994, 39(3):412-438.

[4] Finkelstein S, Hambrick D C. Top-management-team tenure and organizational outcomes: The moderating role of managerial discretion. Administrative Science Quarterly, 1990, 35(3):484-503.

[5] Sambharya, B. (1996). Foreign experience of top management teams and international diversification strategies of U.S. multinational corporations. Strategic Management Journal ,17(9),739-746.

[6] Carpenter A , The Impact of director appointments on board involvement in strategic decision making, Academy of Management Journal, 2001, 44(3):639 660.

[7] Bantel K A .Top management and innovation in banking: does the composition of the top team make a difference, Strategic management Journal, 1989, 10(1):107 124

[8] Richard O C, Barnett T, Dwyer S, et al. Cultural Diversity in Management, Firm Performance, and the Moderating Role of Entrepreneurial Orientation Dimensions, Academy of Management Journal, 2004, 47(2):255-266.

[9] Liu ,X. \& Xue, Y. Research on motivation of strategic change based on the perspective of new CEO, Chinese Journal of Management, 2013, 10(12): 1747.

[10]Liu, X. \& Wang, L. Research on the influence of CEO succession type on strategic change: The mediating role of executive team reorganization, Management Review, 2013, 25(8):102-112.

[11]Helfat C E. Know-How and Asset Complementarity and Dynamic Capability Accumulation: The Case of R\&D, Strategic Management Journal, 2015, 18(5):339-360. 